\title{
Child-Pugh Class C10
}

National Cancer Institute

\section{Source}

National Cancer Institute. Child-Pugh Class C10. NCI Thesaurus. Code C146795.

A total score of 10 for hepatic function, corresponding to class $C$ in the Child-Pugh classification. 